\title{
Exfoliated MoS2 nanosheets loaded on bipolar exchange membranes interfaces as advanced catalysts for water dissociation
}

Li, Jian; Morthensen, Sofie Thage; Zhu, Junyong; Yuan, Shushan ; Wang, Jing ; Volodine , Alexander ; Lin, Jiuyang; Shen , Jiangnan ; Van der Bruggen, Bart

\section{Published in:}

Separation and Purification Technology

Link to article, DOI:

10.1016/j.seppur.2017.11.065

Publication date:

2018

Document Version

Peer reviewed version

Link back to DTU Orbit

Citation $(A P A)$ :

Li, J., Morthensen, S. T., Zhu, J., Yuan, S., Wang, J., Volodine , A., Lin, J., Shen , J., \& Van der Bruggen, B. (2018). Exfoliated MoS nanosheets loaded on bipolar exchange membranes interfaces as advanced catalysts for water dissociation. Separation and Purification Technology, 194, 416-424.

https://doi.org/10.1016/j.seppur.2017.11.065

\section{General rights}

Copyright and moral rights for the publications made accessible in the public portal are retained by the authors and/or other copyright owners and it is a condition of accessing publications that users recognise and abide by the legal requirements associated with these rights.

- Users may download and print one copy of any publication from the public portal for the purpose of private study or research.

- You may not further distribute the material or use it for any profit-making activity or commercial gain

- You may freely distribute the URL identifying the publication in the public portal 


\section{Accepted Manuscript}

Exfoliated $\mathrm{MoS}_{2}$ nanosheets loaded on bipolar exchange membranes interfaces as advanced catalysts for water dissociation

Jian Li, Sofie Thage Morthensen, Junyong Zhu, Shushan Yuan, Jing Wang, Alexander Volodine, Jiuyang Lin, Jiangnan Shen, Bart Van der Bruggen

PII: S1383-5866(17)31873-7

DOI: https://doi.org/10.1016/j.seppur.2017.11.065

Reference: SEPPUR 14221

To appear in: Separation and Purification Technology

Received Date: 13 June 2017

Revised Date: 23 November 2017

Accepted Date: 26 November 2017

Please cite this article as: J. Li, S.T. Morthensen, J. Zhu, S. Yuan, J. Wang, A. Volodine, J. Lin, J. Shen, B. Van der Bruggen, Exfoliated $\mathrm{MoS}_{2}$ nanosheets loaded on bipolar exchange membranes interfaces as advanced catalysts for water dissociation, Separation and Purification Technology (2017), doi: https://doi.org/10.1016/j.seppur. 2017.11.065

This is a PDF file of an unedited manuscript that has been accepted for publication. As a service to our customers we are providing this early version of the manuscript. The manuscript will undergo copyediting, typesetting, and review of the resulting proof before it is published in its final form. Please note that during the production process errors may be discovered which could affect the content, and all legal disclaimers that apply to the journal pertain. 


\section{Exfoliated $\mathrm{MoS}_{2}$ nanosheets loaded on bipolar exchange membranes} interfaces as advanced catalysts for water dissociation

Jian $\mathrm{Li}^{\mathrm{a}}$, Sofie Thage Morthensen ${ }^{\mathrm{b}}$, Junyong Zhu ${ }^{\mathrm{a}}$, Shushan Yuan ${ }^{\mathrm{a}}$, Jing Wang ${ }^{\mathrm{a}, \mathrm{c}}$, Alexander Volodine ${ }^{\mathrm{d}}$, Jiuyang Lin ${ }^{\mathrm{e}}$, Jiangnan Shen ${ }^{\mathrm{f}}$, Bart Van der Bruggen ${ }^{\mathrm{a}, \mathrm{g}}$

${ }^{a}$ Department of Chemical Engineering, KU Leuven, Celestijnenlaan 200F, B-3001 Leuven, Belgium

${ }^{\mathrm{b}}$ Department of Chemical and Biochemical Engineering, Technical University of

Denmark, Søltofts Plads Building 229, 2800 Kongens Lyngby, Denmark

${ }^{c}$ School of Chemical Engineering and Energy, Zhengzhou University, Zhengzhou 450001, China

${ }^{\mathrm{d}}$ Laboratory of Solid State Physics and Magnetism, Celestijnenlaan 200d - box 2414 3001 Leuven

${ }^{\mathrm{e}}$ School of Environment and Resources, Qi Shan Campus, Fuzhou University, No.2 Xueyuan Road, University Town, 350116 Fuzhou, Fujian, China

${ }^{\mathrm{f}}$ Center for Membrane Separation and Water Science \& Technology, Zhejiang University of Technology, Hangzhou, 310014, China

${ }^{\mathrm{g}}$ Faculty of Engineering and the Built Environment, Tshwane University of Technology, Private Bag X680, Pretoria 0001, South Africa

* Corresponding author.

E-mail address: shenjn@ zjut.edu.cn (J. Shen)

bart.vanderbruggen@cit.kuleuven.be (B. Van der Bruggen) 


\begin{abstract}
Over the last few decades, ion exchange membranes have evolved from a laboratory tool to industrial products with significant technical and commercial impacts. Electrodialysis with bipolar membranes (EDBM) is a technology that can produce acids and bases from the corresponding salt solutions. Bipolar membranes are key factors for splitting water at the interface of a cation and anion exchange layer in an electric field. The ideal bipolar membrane should have a low energy consumption, a high current efficiency and long-term stability. In order to investigate the catalytic effect of a monolayer of $\mathrm{MoS}_{2}$, the bipolar membranes were prepared by introducing monolayer $\mathrm{MoS}_{2}$ to the interface of bipolar membranes. The resulting bipolar membrane was found to have lower potential drop, which clearly demonstrates the applicability of the $\mathrm{MoS}_{2}$ layer to act as catalyst. Enhanced acid production confirmed this prediction. Furthermore, a bipolar membrane prepared at $90^{\circ} \mathrm{C}$ had a low swelling ratio of about $7.5 \%$ while maintaining a high water uptake of $71.6 \%$. From the calculation of current efficiency and energy consumption, the bipolar membrane with a monolayer of $\mathrm{MoS}_{2}$ has a higher current efficiency (45\%) and a lower energy consumption $(3.6 \mathrm{~kW} / \mathrm{h} \cdot \mathrm{kg}$ ) compared to a current efficiency of $24 \%$ and an energy consumption of $6.3 \mathrm{~kW} / \mathrm{h} \cdot \mathrm{kg}$ for a bipolar membrane without $\mathrm{MoS}_{2}$. This study proves the catalytic function of $\mathrm{MoS}_{2}$, which lays a foundation for further research on catalytic bipolar exchange membranes.
\end{abstract}

Keywords: Bipolar exchange membrane; $\mathrm{MoS}_{2}$; water dissociation; catalyst; electrodialysis 


\section{Introduction}

Electrodialysis with bipolar membranes (EDBM) is a technology that integrates solvent and salt dissociation, thus inherently has economical and environmental benefits. It has found many interesting applications in the chemical industry [1], in food processing [2], in biochemical industry [3], and in environmental protection [4]. The principle of EDBM lies in the use of a bipolar membrane, which is a laminar structure composed of a cation exchange layer to which an anion exchange layer is added in series. As the electric current passes through, protons and hydroxide ions are generated at the intermediate layer of a bipolar membrane and migrate to the cathode and anode chamber, respectively. The water dissociation observed in bipolar membranes is about 7 orders of magnitude higher than in free solutions [5]. Nevertheless, the actual mechanism of water splitting is still controversial [6].

The ideal bipolar membrane should have a high permselectivity, a low electrical resistance and water splitting voltage drop, a high current efficiency, a good chemical and mechanical stability, long lifetime, and no "ballooning" [7]. However, limitations such as the high membrane cost, insufficient recognition of the importance roles in sustainable development and industrialization, and scarce operation experience still restrict its development. Recently, the chemical composition and structure of the transition region between the anion and the cation exchange layer were modified to improve the water splitting capability. Zhou et al. [8] added nano-ZnO-CeO coupled semiconductors to the anion exchange membrane layer to prepare bipolar membranes, and showed that nano-composites have a better photocatalytic activity for water splitting. Abdu et al. [9] introduced molecularly thin catalyst groups at the interface of the ion exchange layers of a bipolar membrane using the consecutive dipping layer-by-layer (LbL) deposition technology; the outcomes revealed that an additional highly charged thin intermediate layer helps to enhance water splitting. Chen et al. [10] modified the anion and cation layers of a bipolar membrane with copper phthalocyanine tetrasulfonic acid ( $\mathrm{CuTsPc})$ and copper tetraaminophthalocyanine (CuTAPc), respectively. As the catalytic centers of water splitting in the intermediate layers, CuTsPc and CuTAPc speed up the water splitting into hydrogen ions and hydroxyl ions, which lowers the membrane impedance and the voltage drops of the bipolar membranes. With catalyst immobilization, the high activation energy of water dissociation can be reduced by catalytic activity.

Molybdenum disulfide $\left(\mathrm{MoS}_{2}\right)$ has recently demonstrated its functionality as a non-noble metal hydrogen evolution reaction (HER) catalyst with high catalytic efficiency, based on both theoretical and experimental studies [11, 12]. An indirect bandgap for thick $\mathrm{MoS}_{2}$ layers becomes a direct bandgap of $1.8 \mathrm{eV}$ in monolayer $\mathrm{MoS}_{2}$, consisting of two sulfide atomic layers and a layer of sandwiched Mo atoms [13]. This indirect-to-direct band gap transition leads to interesting phenomena in $\mathrm{MoS}_{2}$ monolayers, opening new possibilities for optoelectronic applications [14]. However, a number of studies have revealed that the electrocatalytic HER performance of nanoscale $\mathrm{MoS}_{2}$ mainly arises from its edge states, while the basal 
plane is inert, which leaves a large area of basal planes useless [15]. Ghuman et al. [16] investigated the catalytically active sites for adsorption of $\mathrm{H}_{2} \mathrm{O}, \mathrm{H}$ and $\mathrm{OH}$ species on $\mathrm{MoS}_{2}$ edges, and found that water dissociation can proceed by splitting into adsorbed $\mathrm{OH}$ and $\mathrm{H}$ species; the Mo-edge was the most favorable for adsorption of all species. One explanation of the mechanism of water splitting is the proton transfer reaction. According to the reaction model, the proton and hydroxyl ions are believed to be a result of protonation and deprotonation reactions between water molecules and the fixed charge groups according to the following equations:

$$
\begin{gathered}
\mathrm{B}+\mathrm{H}_{2} \mathrm{O} \rightleftharpoons \mathrm{B} H^{+}+\mathrm{OH}^{-} \\
\mathrm{B} H^{+}+\mathrm{H}_{2} \mathrm{O} \rightleftharpoons \mathrm{B}+\mathrm{H}_{3} \mathrm{O}^{+} \\
A^{-}+\mathrm{H}_{2} \mathrm{O} \rightleftharpoons \mathrm{AH}+\mathrm{OH}^{-} \\
\mathrm{AH}+\mathrm{H}_{2} \mathrm{O} \rightleftharpoons A^{-}+\mathrm{H}_{3} \mathrm{O}^{+}
\end{gathered}
$$

where $\mathrm{A}^{-}$and $\mathrm{BH}^{+}$are the catalytic sites. Following the mechanism of proton transfer, modifying the chemical composition and structure of the transition region is essential in order to improve the water splitting capability of bipolar membranes. The presence of $\mathrm{MoS}_{2}$ enhances the adsorption of $\mathrm{OH}$ and $\mathrm{H}$ species, so that the rate of water dissociation is enhanced. As a result, the high activation energy of water dissociation is reduced. This method can provide an alternative reaction path for bipolar membranes.

So far the hydrophilic/hydrophobic behavior of $\mathrm{MoS}_{2}$ has been discussed without coming to a clear convergence: $\mathrm{MoS}_{2}$ is described as both hydrophilic and hydrophobic [17]. $\mathrm{MoS}_{2}$ is thermally and mechanically stable, featuring a melting point reaching $1185{ }^{\circ} \mathrm{C}$. Aqueous dispersions of two-dimensional $\mathrm{MoS}_{2}$ has shown a low cytotoxicity and high biocompatibility, which renders it suitable for water application [18]. Metal oxides or silicon groups, as well as metal hydroxides, have been examined as possible catalysts to enhance the water-splitting capability of bipolar membranes [19]. However, this is no report on $\mathrm{MoS}_{2}$ to tailor the interface of bipolar membranes.

In this work, polyepichlorohydrin (PECH) with an inherent chloromethyl group is employed as the polymer matrix of an anion exchange membrane. Due to the inherent chloromethyl groups, the reaction steps can be reduced. In order to obtain high performance bipolar membranes with good mechanical stability and to maintain a certain ion exchange capacity, polyvinylidene fluoride (PVDF) was adopted as supporting material. PVDF is a widely used membrane material with antioxidation activity, great chemical resistance, thermal stability, high mechanical strength, and suitable membrane-forming characteristics [20]. The addition of PECH into a PVDF polymer matrix can improve the thermal properties, dimensional stability, and mechanical strength. The PVDF/PECH composite polymer membrane was obtained by directly blending PVDF polymer and PECH polymer in solutions. As sulfonated polyethersulfone (SPES) contains many polar groups along the back-bone chain [21] and is stable under acidic conditions [22], it was chosen as the cation exchange layer. To evaluate the advantages of this strategy, bipolar membranes were fabricated through conventional multi-layer casting and the performance was compared with the membranes having a $\mathrm{MoS}_{2}$ layer at the interface. 


\section{Experimental}

\subsection{Materials}

Polyepichlorohydrin (PECH, average molecular weight: $700000 \mathrm{Da}$ ) was purchased from J\&K Scientific Ltd. (Beijing, China). Polyvinylidene fluoride (PVDF) (grade Solefs 6020) was purchased from Solvay. Trimethylamine (TMA) was purchased from Sigma-Aldrich. Dimethyl sulfoxide (DMSO) and dimethylformamide (DMF) were purchased from Sigma-Aldrich. $\mathrm{MoS}_{2}$ was purchased from Chempur (Germany). Commercial CEM (FKS-PET-130), AEM (Fumaseps FAB) membranes and bipolar membranes (Fumaseps FBM) were purchased from FuMA-Tech (Germany). These membranes were selected because of their high permselectivity, low resistivity and very high mechanical stability. All other chemicals were commercially obtained and used without further purification.

\subsection{Preparation of Bipolar Membranes}

The bipolar membranes with $\mathrm{MoS}_{2}$ were prepared by casting in a four steps method: (1) cation exchange layer preparation; (2) $\mathrm{MoS}_{2}$ layer preparation; (3) anion exchange layer preparation; (4) amination.

1. Cation exchange layer preparation. $3 \mathrm{~g}$ SPES was fully dissolved in $17 \mathrm{~g}$ DMF. After degassing by ultrasound, it was casted onto a clean glass plate and kept in a $60^{\circ} \mathrm{C}$ vacuum drying oven for $24 \mathrm{~h}$ to remove the solvent.

2. $\mathrm{MoS}_{2}$ layer preparation. $2 \mathrm{D} \mathrm{MoS}_{2}$ flakes were prepared from $\mathrm{MoS}_{2}$ bulk powder using a grinding-assisted liquid-phase exfoliation technique, which was similar to a method reported elsewhere [23, 24]. 10 gram of $\mathrm{MoS}_{2}$ powder was added to $5 \mathrm{~mL} \mathrm{H}_{2} \mathrm{O}$ and $5 \mathrm{~mL}$ ethanol solution and stirred for 30 min. The slurry was then sonicated for $120 \mathrm{~min}$ and finally centrifuged for 45 min at $4000 \mathrm{rpm}$. The supernatant containing $2 \mathrm{D} \mathrm{MoS}_{2}$ nanoflakes was collected. The collected supernatant was tipped on the surface of SPES membranes. The supernatant containing the $\mathrm{MoS}_{2}$ was dried in a vacuum oven for $12 \mathrm{~h}$ to remove the solvent.

3. Anion exchange layer preparation. $2 \mathrm{~g}$ PECH and $2 \mathrm{~g}$ PVDF were dissolved at $80{ }^{\circ} \mathrm{C}$ in $25 \mathrm{~mL}$ DMSO in a round bottom flask until the mixture dissolved completely. After the mixture was cooled to room temperature, the solution was cast on the surface of the former membrane with $\mathrm{MoS}_{2}$. The assembled bipolar membrane was then placed in an oven at $60{ }^{\circ} \mathrm{C}$ for $12 \mathrm{~h}$ and then the membrane was peeled off from the glass plate.

4. Amination. The membrane was immersed in TMA solution ( $2 \mathrm{~mL} 24 \%$ TMA in $100 \mathrm{~mL}$ ) at different temperature for different times. Afterwards, the obtained membrane was fully washed by water to remove the rest TMA and 
finally stored for further use. The reaction process can be seen in Fig. 1.

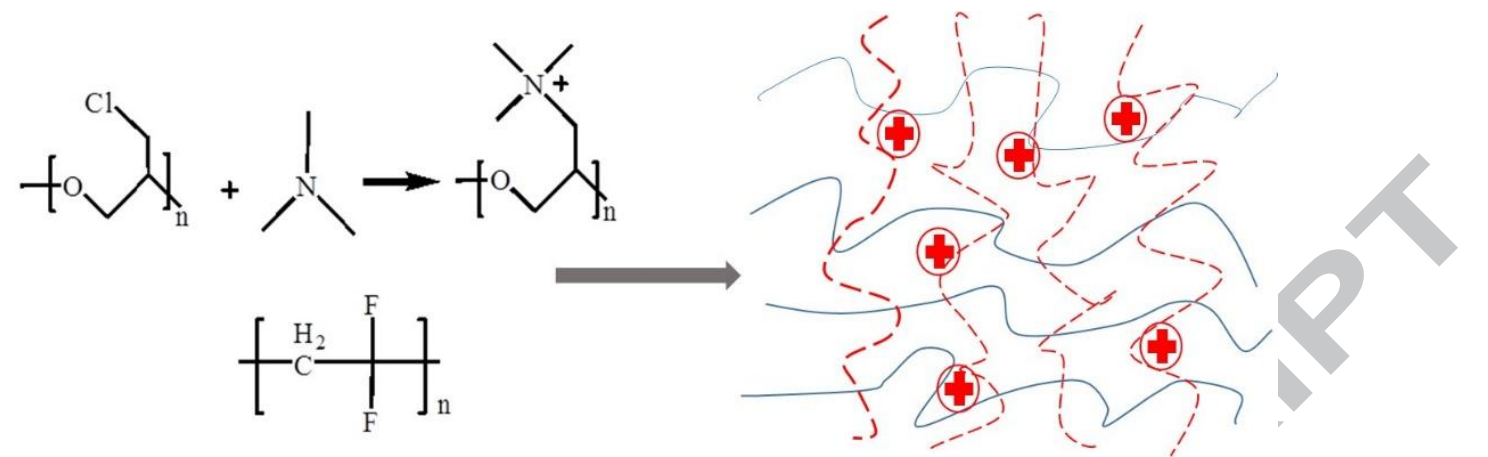

Fig. 1 The amination reactions as well as the interpenetrating polymer networks of anion-exchange layers

In comparison with bipolar membranes with $\mathrm{MoS}_{2}$, the preparation method of blank experiments was similar to the previous procedure, except that step 2 was not included.

\subsection{Characterization of $\mathrm{MoS}_{2}$}

Samples for AFM were prepared by drop-casting $10 \mu \mathrm{L}$ of each suspension onto a cation exchange membrane and heating at $40{ }^{\circ} \mathrm{C}$ to evaporate the solvent. Conductive AFM images were obtained using a Bruker MultiMode with an installed Peak Force TUNA module (MM8-PFTUNA for MultiMode8 AFM system, Germany).

\subsection{Characterization of bipolar membranes}

The physical morphologies and structures of nanofiber mats and bipolar membranes (the cross-sections and surfaces) were observed using high resolution scanning electron microscopy (Sirion 200, Philips). All specimens were sputter-coated with Au before testing.

The characteristic functional groups of bipolar membrane surface were recorded by Fourier transform infrared (FTIR). Membrane samples were scanned from 750 to $4000 \mathrm{~cm}^{-1}$ by using a Nicolet-6700 spectrometer with a resolution of $4 \mathrm{~cm}^{-1}$.

Water uptake was based on the water retention inside the membrane (dry membrane as a reference) and determined at the room temperature. The membranes were dried at $60{ }^{\circ} \mathrm{C}$ in an oven and then weighed accurately followed by immersing in deionized water for at least $24 \mathrm{~h}$ to ensure complete equilibrium and then reweighed after removing surface water. The water uptake was calculated as follows:

$$
\text { Water uptake }=\frac{W_{w e t}-W_{d r y}}{W_{d r y}} \times 100 \%
$$

where the $\mathrm{W}_{\text {wet }}$ and $\mathrm{W}_{\text {dry }}$ are the weights of the membrane sample under wet 
condition and dry condition, respectively.

The linear swelling ratio (LSR) was calculated based on the change of length of membranes ( $1 \mathrm{~cm}$ in width and $4 \mathrm{~cm}$ in length) before and after immersing in water at $25^{\circ} \mathrm{C}$ for $24 \mathrm{~h}$. It was calculated by the following equation:

$$
\mathrm{LSR}=\frac{l_{w}-l_{d}}{l_{d}} \times 100 \%
$$

where $l_{\mathrm{w}}$ and $l_{\mathrm{d}}$ are the membrane's length under wet condition and dry condition, respectively.

The static contact angles of the membrane surface were measured by a contact angle goniometer (OCA-20, Data-physics, Germany) at ambient temperature. The water droplet morphologies and contact angles were analyzed by an optical contact angle meter. At least five drops at different positions on the membrane surface was measured.

The ion exchange capacity (IEC) of the membrane was determined by titration. Before the measurement, the membrane was soaked in $1 \mathrm{~mol} / \mathrm{L} \mathrm{HCl}$ solution for $24 \mathrm{~h}$ to reach the final dilation. Then, it was taken out of the solution and carefully wiped with absorbent paper. Finally, the membrane was immersed in $100 \mathrm{~mL} 1 \mathrm{M} \mathrm{NaCl}$ solution for $24 \mathrm{~h}$. The solution was titrated against $0.01 \mathrm{~mol} / \mathrm{L} \mathrm{NaOH}$ using phenolphthalein as indicator. The IEC of a cation exchange membrane was calculated from the following formula [10]:

$$
\operatorname{IEC}\left(\frac{\mathrm{mmol}}{\mathrm{g}}\right)=\frac{n_{\mathrm{HCl}}}{W_{\text {dried }}}
$$

where $n_{\mathrm{HCl}}$ is the milli-equivalent of $\mathrm{H}^{+}$ions determined by $\mathrm{NaOH} . \mathrm{W}_{\text {dried }}$ was the mass of dried membrane sample (g). The IEC of anion exchange membrane was determined in the same way but the soaked solution was alkaline and titration solution was acid.

The mechanical properties of bipolar membranes were investigated using a tensile testing equipment (Type 4505, Instron, Nordwood, U.S.) at room temperature at a constant crosshead speed of $1 \mathrm{~mm} / \mathrm{min}$. The samples were cut into two strips with $2 \mathrm{~mm}$ width. Measurements were performed with membranes dried at room temperature for 3 hours. Load extension graphs were obtained and converted to stress-strain curves by applying the following equations:

$$
\begin{aligned}
& \text { Stress }(\sigma)=\frac{F}{A} \\
& \text { Strain }(\varepsilon)=\frac{\Delta l}{L}
\end{aligned}
$$

where $\mathrm{F}$ is the applied force $(\mathrm{N}), \mathrm{A}$ is the cross sectional area $\left(\mathrm{m}^{2}\right), \Delta \mathrm{l}$ is the change in length $(\mathrm{mm})$ and $\mathrm{L}$ is the length between clamps $(40 \mathrm{~mm})$.

The determination procedure of the ion transport rate of a bipolar membrane was as follows: a cation exchange membrane was fixed between the cathode chamber and the anode chamber as a separator. The catholyte was $1 \mathrm{~mol} / \mathrm{L} \mathrm{Na} \mathrm{SO}_{4}$ solution, and the anolyte was $0.5 \mathrm{~mol} / \mathrm{L} \mathrm{H}_{2} \mathrm{SO}_{4}$ solution. The volumes of the catholyte and the anolyte were $200 \mathrm{~mL}$. A constant current was supplied by a direct current source (DF1720SB5A, Zhejiang Zhongce Electronic Co., Ltd. in China). The current density 
was $10 \mathrm{~mA} \mathrm{~cm}^{-2}$. The $\mathrm{H}^{+}$concentration in the cathode chamber was measured after 1 $\mathrm{h}$ transport.

To determine the ion transport rate of an anion exchange membrane, the process was similar as the procedure of a cation exchange membrane: an anion membrane was fixed between the cathode chamber and the anode chamber as a separator. The catholyte was $1 \mathrm{~mol} / \mathrm{L} \mathrm{NaOH}$ solution, and the anolyte was $1 \mathrm{~mol} / \mathrm{L} \mathrm{Na}_{2} \mathrm{SO}_{4}$ solution. The $\mathrm{OH}^{-}$concentration in the anode chamber was measured after $1 \mathrm{~h} \mathrm{[10].}$

The current-voltage curves of bipolar membranes were recorded at $25{ }^{\circ} \mathrm{C}$ through a two-compartment measuring technique (Fig. 2). The effective bipolar membranes area was $13.84 \mathrm{~cm}^{2}$ and the working electrolytes of electrode were 0.5 $\mathrm{mol} / \mathrm{L} \mathrm{NaCl}$ solutions. The current was supplied by a programmable DC power system (DF1720SB5A, Zhejiang Zhongce Electronic Co., Ltd. in China) and applied into the cell by two carbon electrodes. The voltage drop was measured using a voltmeter (ZW1418, Qingdao Qingzhi Instruments Co., China) by two platinum filaments located approximately $1.0 \mathrm{~mm}$ away from each membrane surface. The membrane sample was inserted between two half-cells.

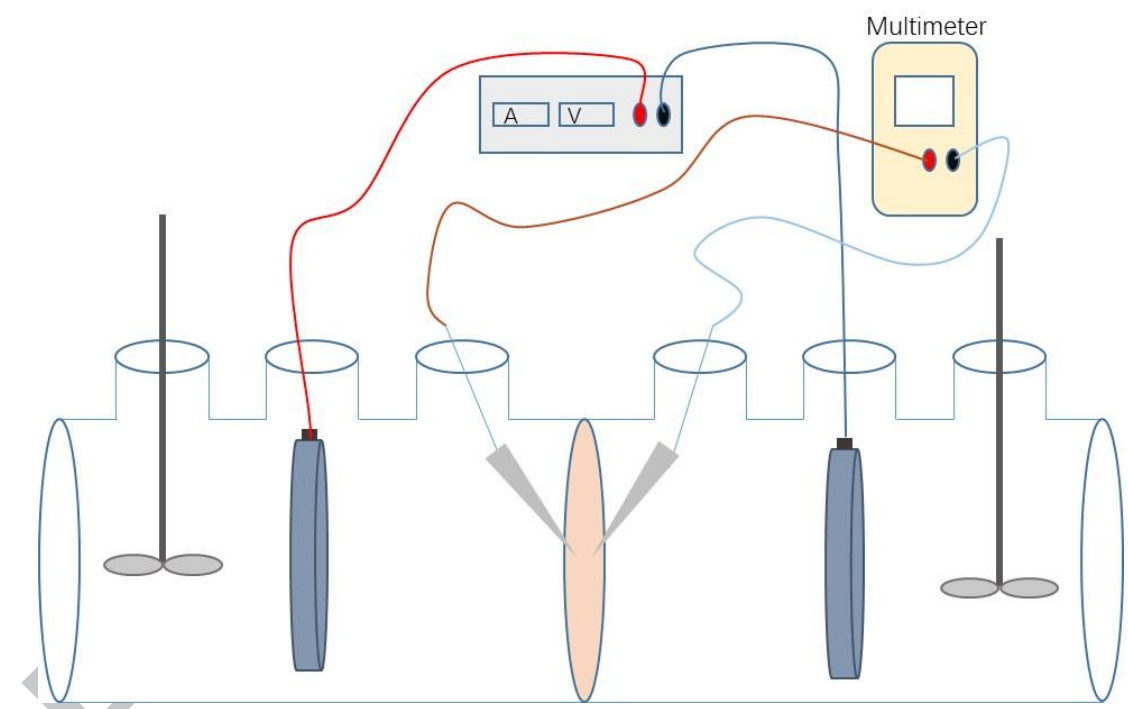

Fig. 2 The experimental setup for I-V curves: current electrodes, silver electrode, and bipolar membrane

The water dissociation performance of bipolar membranes was determined using a simple four-compartment electrodialysis stack as shown in Fig. 3. The effective membrane area was $7.07 \mathrm{~cm}^{2}$ and all the four compartments were filled with 0.5 $\mathrm{mol} / \mathrm{L} \mathrm{Na}_{2} \mathrm{SO}_{4}$ solution as the electrolytes at constant current $\left(20 \mathrm{~mA} / \mathrm{cm}^{2}\right)$. The water dissociation time was $1 \mathrm{~h}$ and the yield of acid and base was determined by classical acid-base titration. 


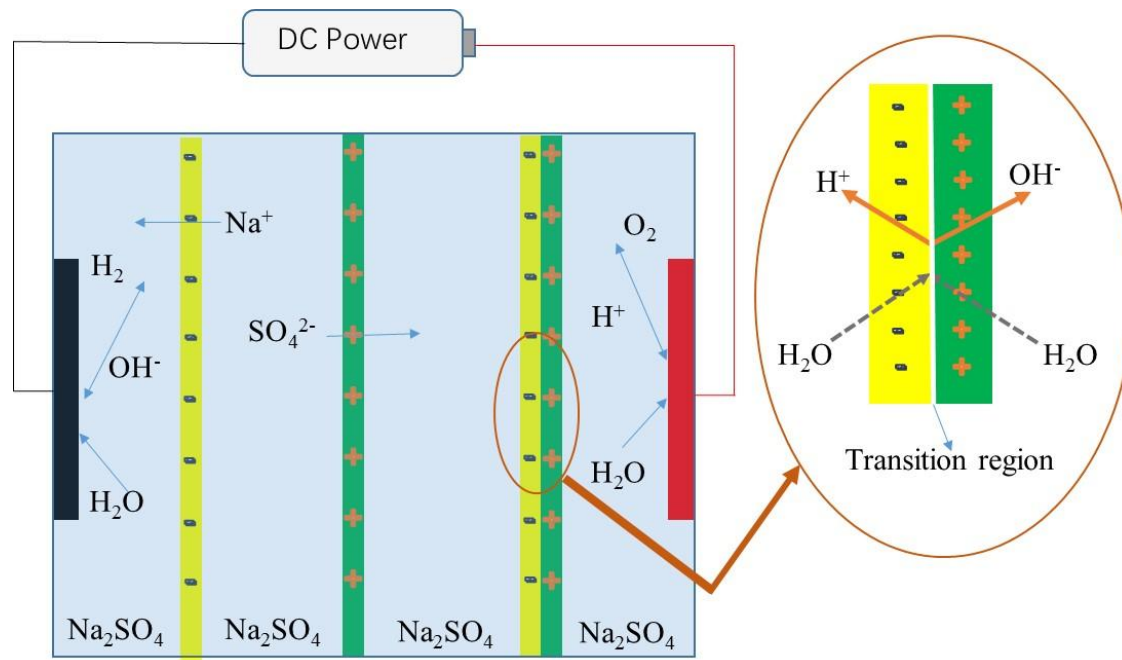

Fig. 3 The electrodialysis stack to detect acid production

The current efficiency was calculated as:

$$
\text { Current efficiency }=\frac{N}{n I t / F} \times 100 \%=\frac{N F}{n I t} \times 100 \%
$$

where $\mathrm{N}$ is the equivalent of sulfuric acid, $\mathrm{n}$ is the number of bipolar membranes ( $\mathrm{n}=1$ in this research), and $\mathrm{F}$ is the Faraday constant $\left(96,500 \mathrm{C} \mathrm{mol}^{-1}\right.$ ), I is the current, and $t$ is the experimental time.

The energy consumption $\mathrm{E}\left(\mathrm{kW} \mathrm{h} \mathrm{kg}^{-1}\right)$ was calculated as:

$$
\mathrm{E}=\int \frac{U I d t}{C_{t} V M}
$$

where $U$ is the voltage drop across the EDBM stack, $I$ is the current, $C_{t}$ is the concentration of sulfuric acid at time $t, V$ is the volume of the acid cycle $\left(0.25 \mathrm{dm}^{-3}\right)$, and $\mathrm{M}$ is the molar mass of sulfuric acid $\left(98.08 \mathrm{~g} \mathrm{~mol}^{-1}\right)$.

\section{Results and discussion}

\subsection{SEM}

The surface morphology of the prepared composite membranes was observed by SEM as shown in Fig. 4a, b and d. A cation exchange membrane made by SPES shows smooth and uniform surfaces. For an anion exchange membrane composed by PECH/PVDF, a surface morphology without any obvious phase separation can be observed, indicating that PECH and PVDF are compatible. The surface of the prepared anion exchange membrane had pores, which may have two reasons: first, interpenetrating polymer networks cast on a substrate and coagulated to form pores [25]; second, during amination, membranes become more hydrophilic, and the solvent locally remained on the internal copolymers. Then the solvent was removed from the 
copolymers; therefore, macro-pores remained at the location of the removed solvent [26].

The cross section of bipolar membranes is shown in Fig. 4e and f. A blurred inter layer was observed in the two layer bipolar membranes, this is because the anion exchange polymer dissolved and mixed with the cation exchange polymer during the casting process. For three layer bipolar membranes, a sharp junction between the anion- and the cation-exchange layers was formed, which is because the occurrence of $\mathrm{MoS}_{2}$ hinders the contact between the two polymers. The $\mathrm{MoS}_{2}$ nanostructure morphology was preserved in Fig. 4c after exfoliation: from the SEM images of the membrane after step 2, a full coverage of monolayer $\mathrm{MoS}_{2}$ was found. The exfoliated nanosheets were disordered and compressed onto the membrane surface. From the SEM images, it can be concluded that exfoliation of $\mathrm{MoS}_{2}$ was successful. For all the membranes, no bubbles and cracks at the inter layer were observed.
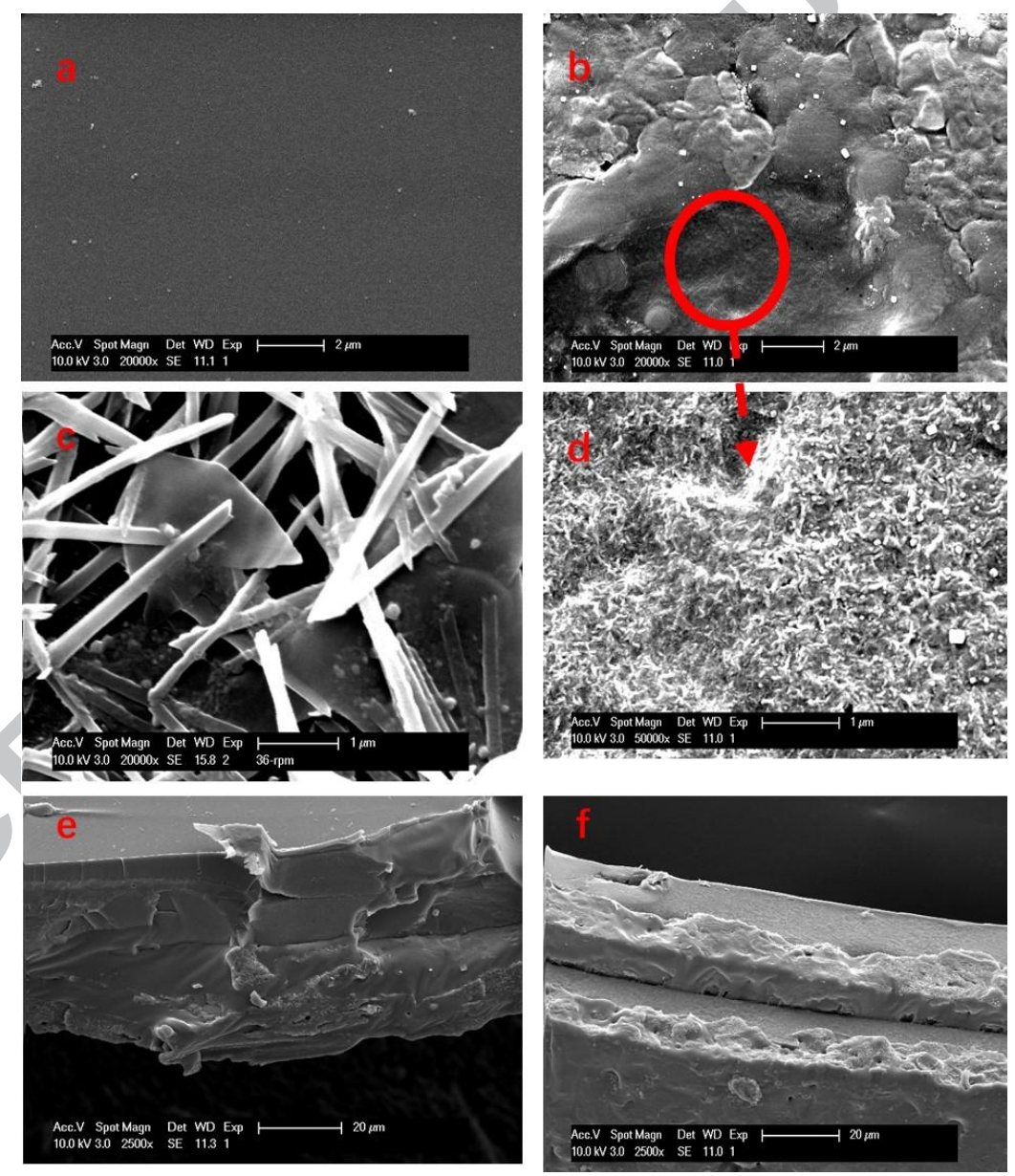

Fig. 4 SEM images of bipolar membranes and cross-section (a: cation exchange layer surface; $b$ and d: anion exchange layer surface; c: $\mathrm{MoS}_{2}$ images after step 2; e: cross-section image of bipolar membrane without $\mathrm{MoS}_{2} ; \mathrm{f}$ : cross-section image of bipolar membrane with $\mathrm{MoS}_{2}$ )

\subsection{AFM of $\mathrm{MoS}_{2}$}

To further confirm the morphology and thickness of the exfoliated $\mathrm{MoS}_{2}$, atomic 
force microscopy (AFM) topography images of these nanostructures were analyzed (Fig. 5). The AFM images shown in Fig. 5a and b demonstrate the uniformity of $\mathrm{MoS}_{2}$ sheet coverage on mica substrates. A thickness of about $18 \mathrm{~nm}$ of vapor-deposited $\mathrm{MoS}_{2}$ was obtained on the substrate, which corresponds to the thickness of the inter layer of bipolar membranes. Further analysis of the monolayer $\mathrm{MoS}_{2}$ were exhibited at Fig. 5c, d and e, indicating that a mean longest diagonal of $100 \mathrm{~nm}$ with an average thickness of $4 \mathrm{~nm}$ was obtained.
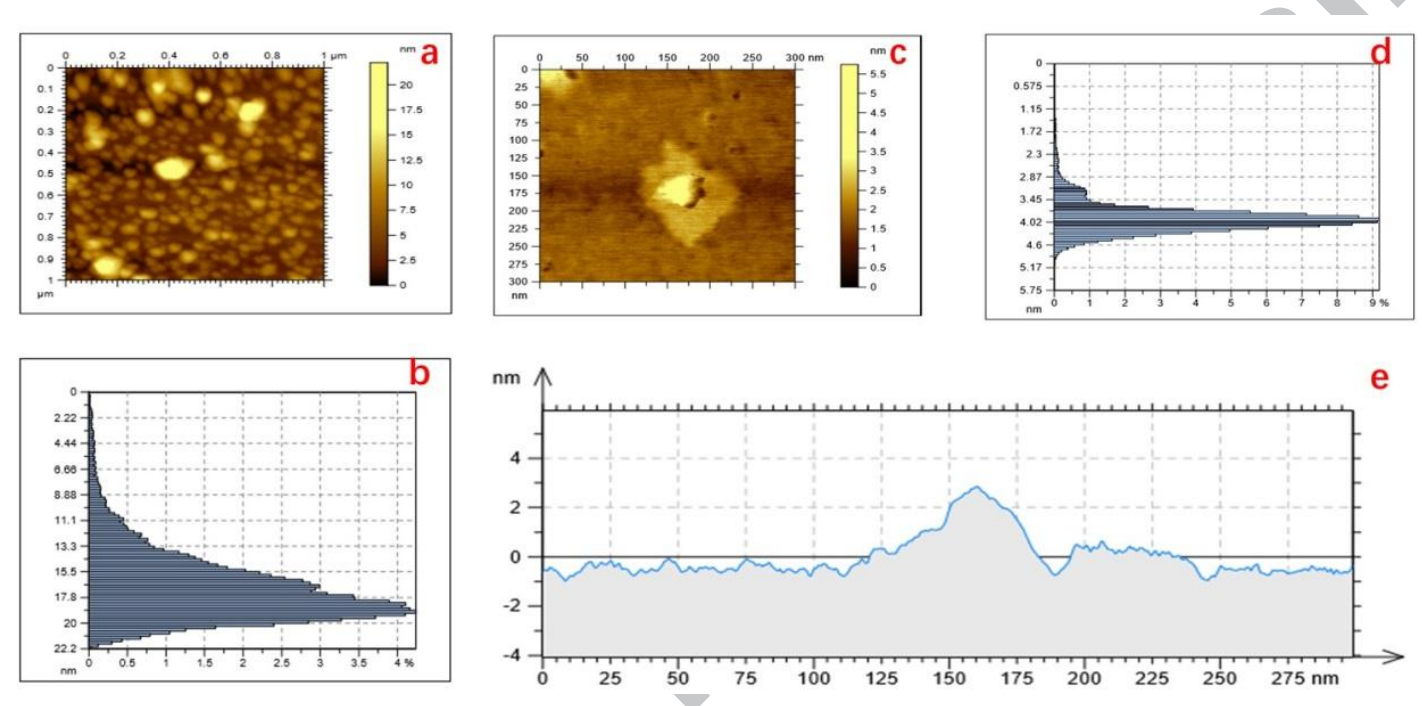

Fig. 5 Atomic force microscopy (AFM) micrograph of $\mathrm{MoS}_{2}$ nanosheets

\subsection{FT-IR spectra}

The FT-IR spectra of the bipolar membrane are shown in Fig. 6. The absorption peaks at approximately $1,026 \mathrm{~cm}^{-1}$ are characteristic of the aromatic $\mathrm{SO}_{3} \mathrm{H}$ symmetric stretching vibrations, with those of $1,235 \mathrm{~cm}^{-1}$ for the asymmetric $\mathrm{O}=\mathrm{S}=\mathrm{O}$ and 1,080 $\mathrm{cm}^{-1}$ for the symmetric $\mathrm{O}=\mathrm{S}=\mathrm{O}$ stretching vibrations [21]. The strong absorption appearing around $1106 \mathrm{~cm}^{-1}$ for the SPES membrane is due to the presence of the aromatic ring [27], while the strong absorption appearing around $1297 \mathrm{~cm}^{-1}$ for the two membranes is assigned to the presence of $\mathrm{O}=\mathrm{S}=\mathrm{O}$ ester sulfone [28].

For the opposite side, the strong peak appearing at $1402 \mathrm{~cm}^{-1}$ corresponds to $\mathrm{CF}$ stretching vibrations. The $\mathrm{C}-\mathrm{C}$ band of PVDF is clearly observed at $1165 \mathrm{~cm}^{-1}$ [29]. Compared with the pure PVDF membrane, the composite membranes exhibited some new peaks. The peaks at 2878 and $2923 \mathrm{~cm}^{-1}$ were attributed to the stretching vibration of the aliphatic $\mathrm{C}-\mathrm{H}$ bond on the methyl or methylene groups of $\mathrm{PECH}$ [30]. The peak at $976 \mathrm{~cm}^{-1}$ was assigned to the $\mathrm{C}-\mathrm{N}$ vibration of the quaternary ammonium groups [31]. The characteristic peak at $1560 \mathrm{~cm}^{-1}$ represents the typical stretching vibration of $\mathrm{C}-\mathrm{N}$ peaks. All the observations confirmed successful blend of PECH-PVDF and successful introduction of functional groups for the bipolar membranes. 


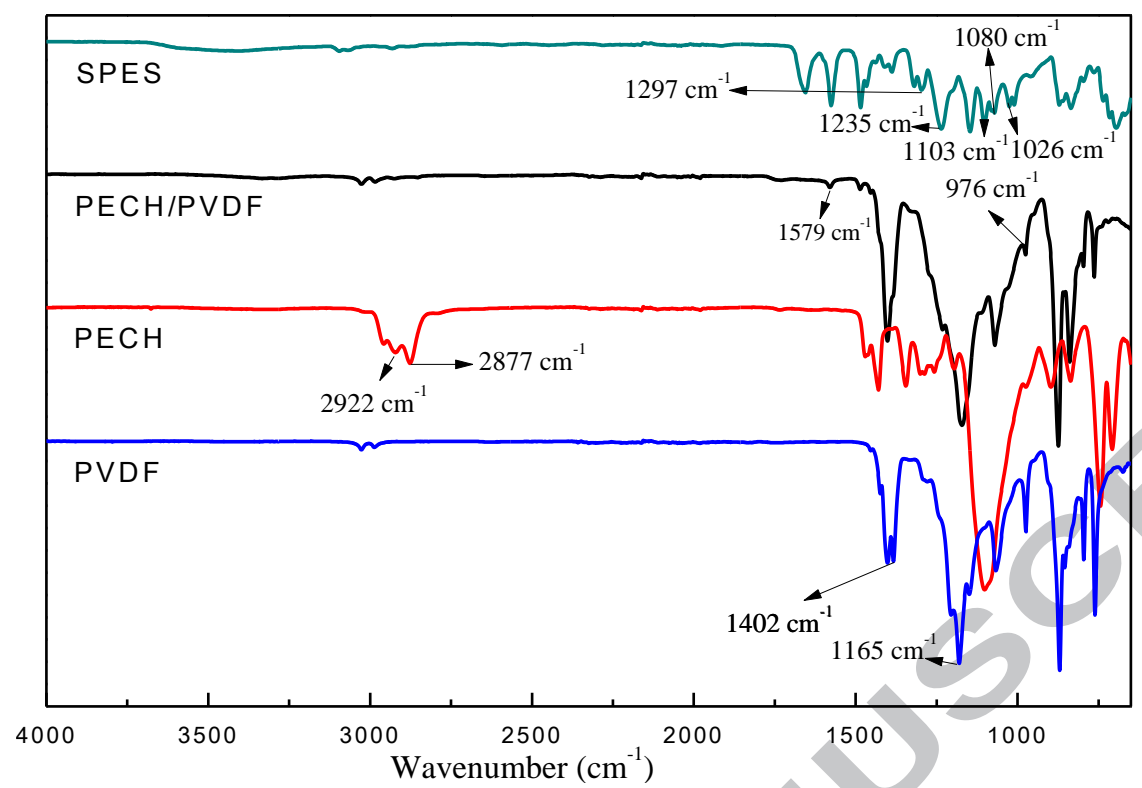

Fig. 6 FTIR spectra of bipolar membranes

\subsection{Contact angle, water uptake, swelling ratio and ion}

\section{exchange capacity}

The water uptake and swelling ratio of the ion exchange membranes can greatly influence the performance when used in electrodialysis. Membranes with a higher water uptake tend to have a high ionic conductivity while an excessively high water uptake would reduce the dimensional and thermal stability. After amination by TMA solution, bipolar membranes have a low swelling radio at about $7.5 \%$ while maintain a high water uptake of $71.6 \%$ at room temperature. The contact angles of anion exchange membranes decrease remarkably after amination as can be seen in Fig. 7 . This indicates that the increase of the functional groups on the surface would elevate the hydrophilic properties. The ion exchange capacity for anion exchange layer after amination and cation exchange layer is 1.05 and $0.93 \mathrm{mmol} / \mathrm{g}$, respectively. Obviously, amination reaction has a fundamental effect on bipolar membranes properties. 


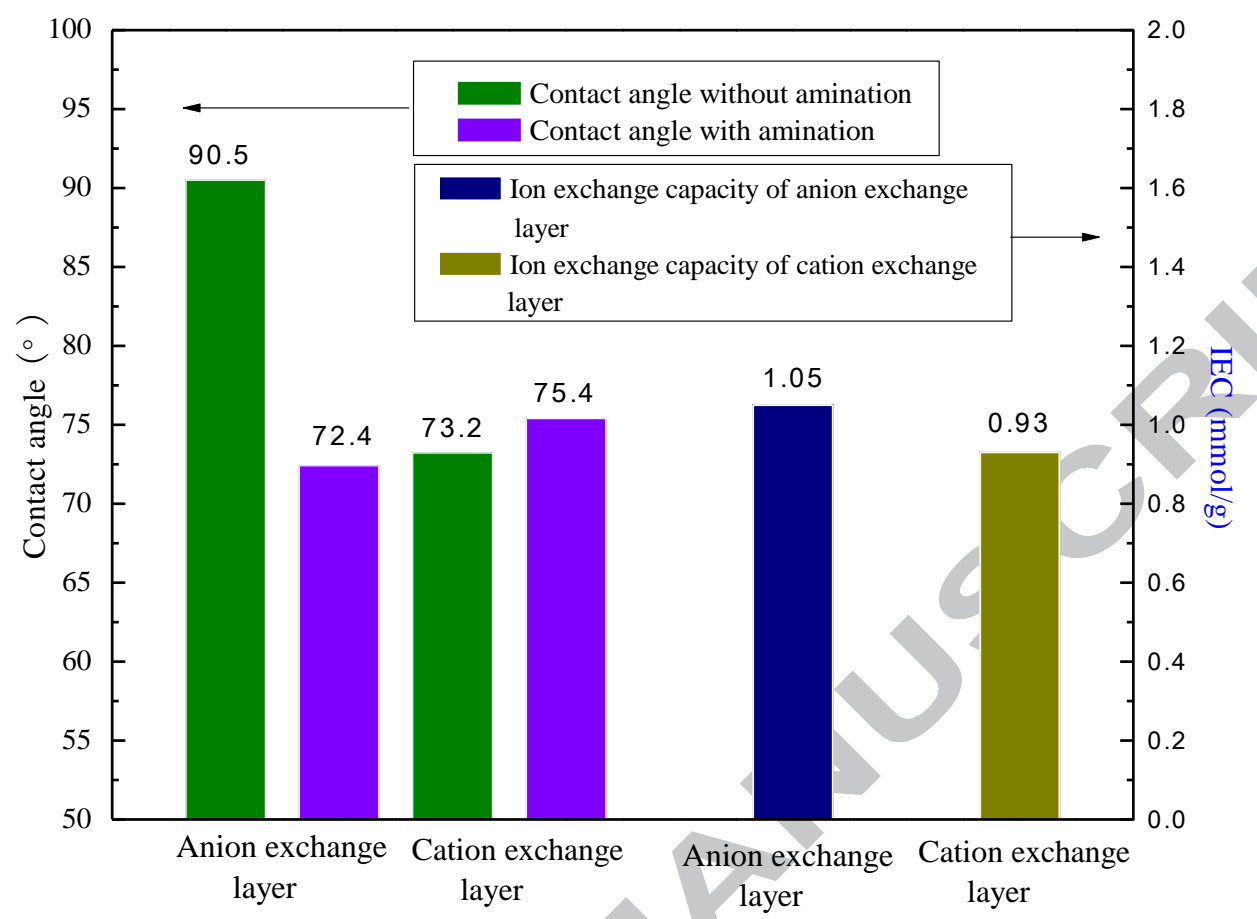

Fig. 7 Contact angle and IEC of bipolar membranes

\subsection{Mechanical strength and ion transport rate of bipolar membranes}

For bipolar membrane prepared at $90^{\circ} \mathrm{C}$ with $\mathrm{MoS}_{2}$, a typical stress-strain curve was shown in Fig. 8. It can be seen that the stress-strain curves display an elastic behavior with continuously applied stress until the membrane break. The prepared bipolar membrane presented a break stress of approximately $20 \mathrm{MPa}$ but with only $2.5 \%$ of elongation at break. Consequently, the above results suggest that the bipolar membrane possess robust mechanical strength with high water uptake. 


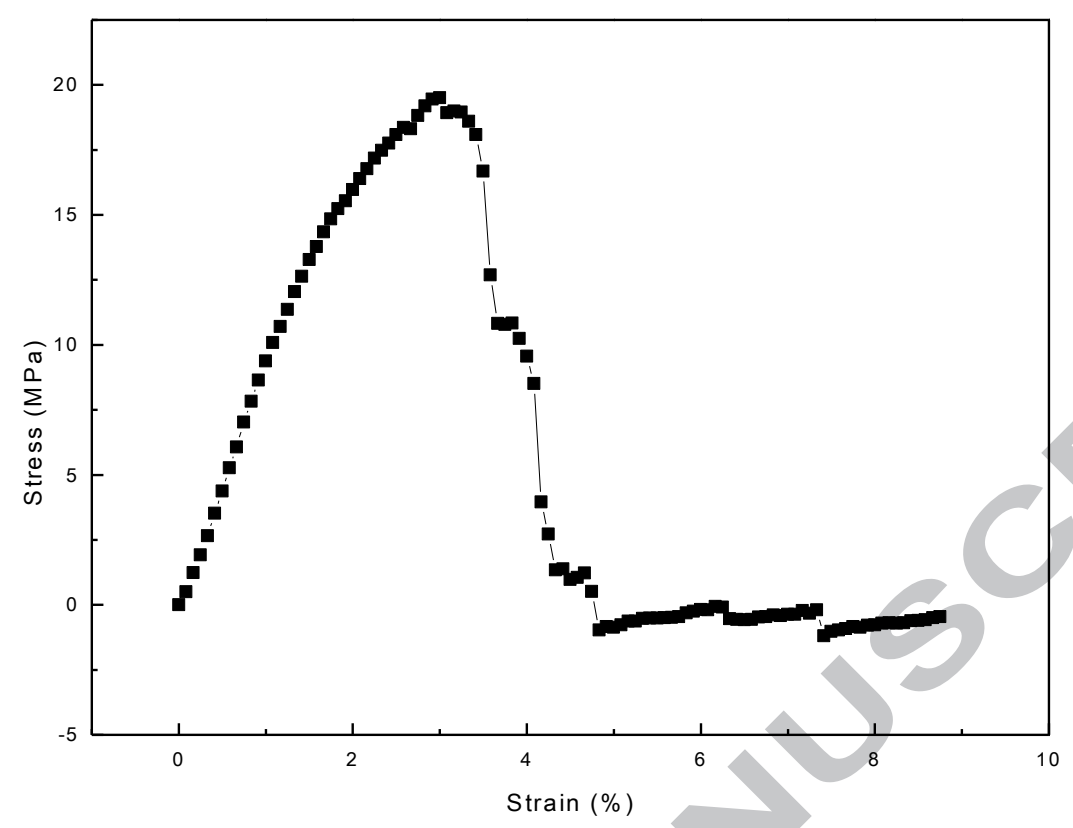

Fig. 8 Stress-strain curves of the prepared bipolar membrane with $\mathrm{MoS}_{2}$

Protons migrate from the anode chamber to the cathode chamber through anion exchange membranes with the assistance of the electrical field. The concentration change of $\mathrm{H}^{+}$in the cathode chamber within $1 \mathrm{~h}$ was $0.19 \mathrm{~mol} / \mathrm{L}$. Similarly, the concentration change of $\mathrm{OH}^{-}$in the anode chamber within $1 \mathrm{~h}$ was $0.23 \mathrm{~mol} / \mathrm{L}$. The high concentration change was attributed to the high ion exchange capacity and the pores in the membrane matrix.

\subsection{Current-voltage curves}

Fig. 9 illustrates the effect of $\mathrm{MoS}_{2}$ addition and amination temperature on the $\mathrm{I}-\mathrm{V}$ curves of the prepared bipolar membranes. In comparison to the $\mathrm{I}-\mathrm{V}$ curve of the bipolar membrane prepared without $\mathrm{MoS}_{2}$, the membrane with an extra $\mathrm{MoS}_{2}$ interface has a dramatically lower voltage drop. This indicates that $\mathrm{MoS}_{2}$ is an excellent electrocatalyst that can catalyze water dissociation. In addition, mono-layer $\mathrm{MoS}_{2}$ as inter-layer catalyst increased the junction electric field. The variations of amination temperature significantly affect the voltage drop across the bipolar membranes. Compared with bipolar membranes prepared at lower temperature, the voltage drop at $90{ }^{\circ} \mathrm{C}$ was $4.23 \mathrm{~V}$, which is $18 \%$ lower than the blank one at the current density of $57.7 \mathrm{~mA} / \mathrm{cm}^{2}$. Since a higher temperature can enhance the amination reaction, the junction electric field is increased. Thus, the efficiency of water dissociation is promoted, and the membrane resistance is reduced. On the other hand, the hydrophilic groups on the surface of the anion exchange membranes enhance the hydrophilicity of the bipolar membranes. Consequently, more water molecules transfer into the inter-layer to compensate for the water consumption in the interlayer and further promote water dissociation to $\mathrm{OH}^{-}$and $\mathrm{H}^{+}$ions. Finally, 
although quaternary ammonium groups have a very weak catalytic activity for water dissociation, they can degrade to tertiary and secondary amines in a high electric field in alkaline conditions, and become more reactive [32]. However, the voltage drop is still slightly higher compared to the commercial bipolar membranes.

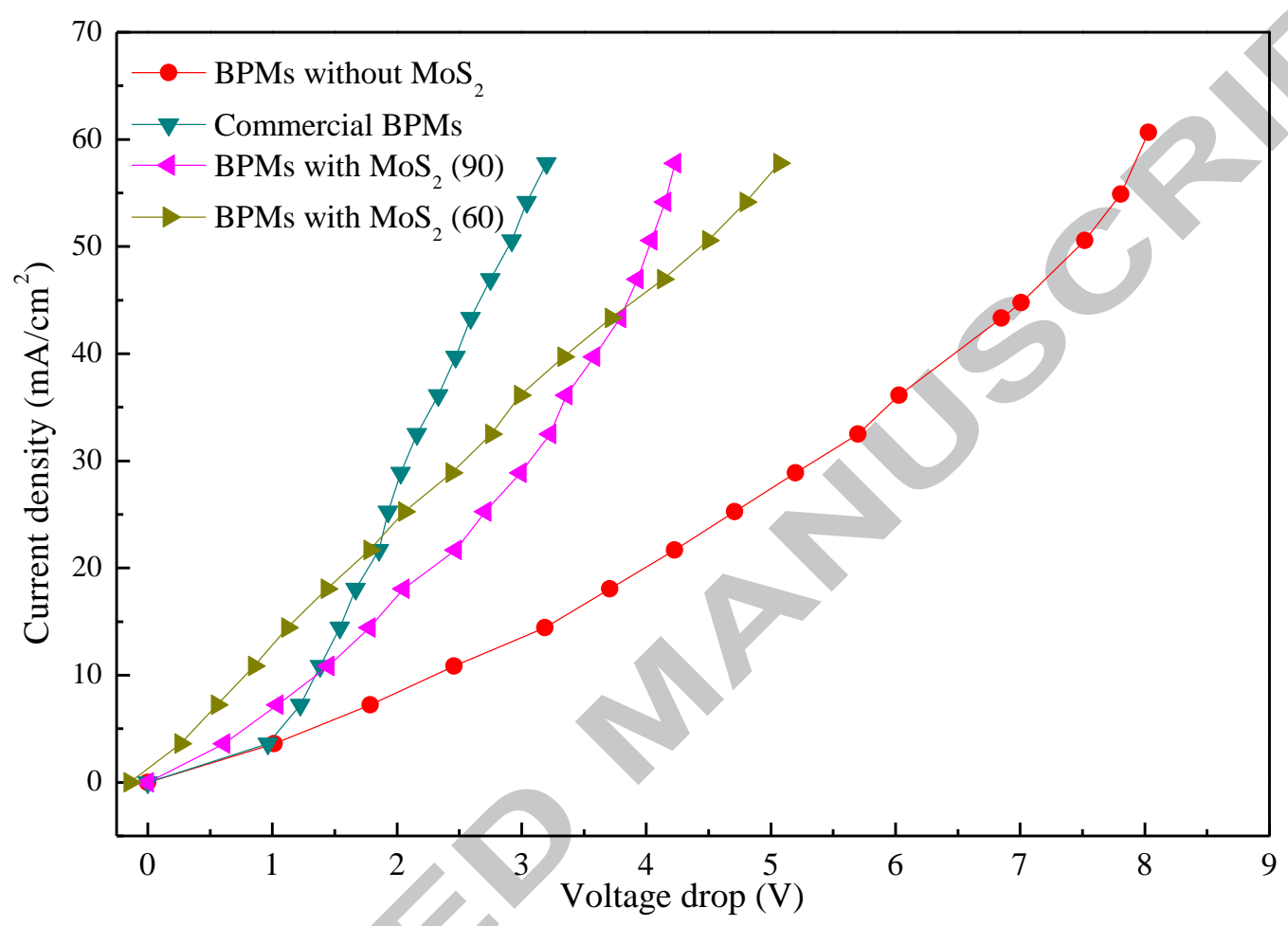

Fig. 9 The I-V curves of the bipolar membranes (BPMs: bipolar membranes)

\subsection{Water dissociation performance of bipolar membranes}

To investigate the water dissociation of the new bipolar membrane with $\mathrm{MoS}_{2}$ as the intermediate layer, a water dissociation test was conducted at a current density of $20 \mathrm{~mA} / \mathrm{cm}^{2}$. Fig. 10 shows the yields for water dissociation using bipolar membranes prepared by different methods. Obviously, the concentration of acid increased with time. However, as the reaction temperature increased, membranes exhibit a better acid yield. Furthermore, the bipolar membrane with $\mathrm{MoS}_{2}$ produces much more acid than the blank membrane, suggesting that the water dissociation is enhanced after introducing $\mathrm{MoS}_{2}$ as intermediate layer. 


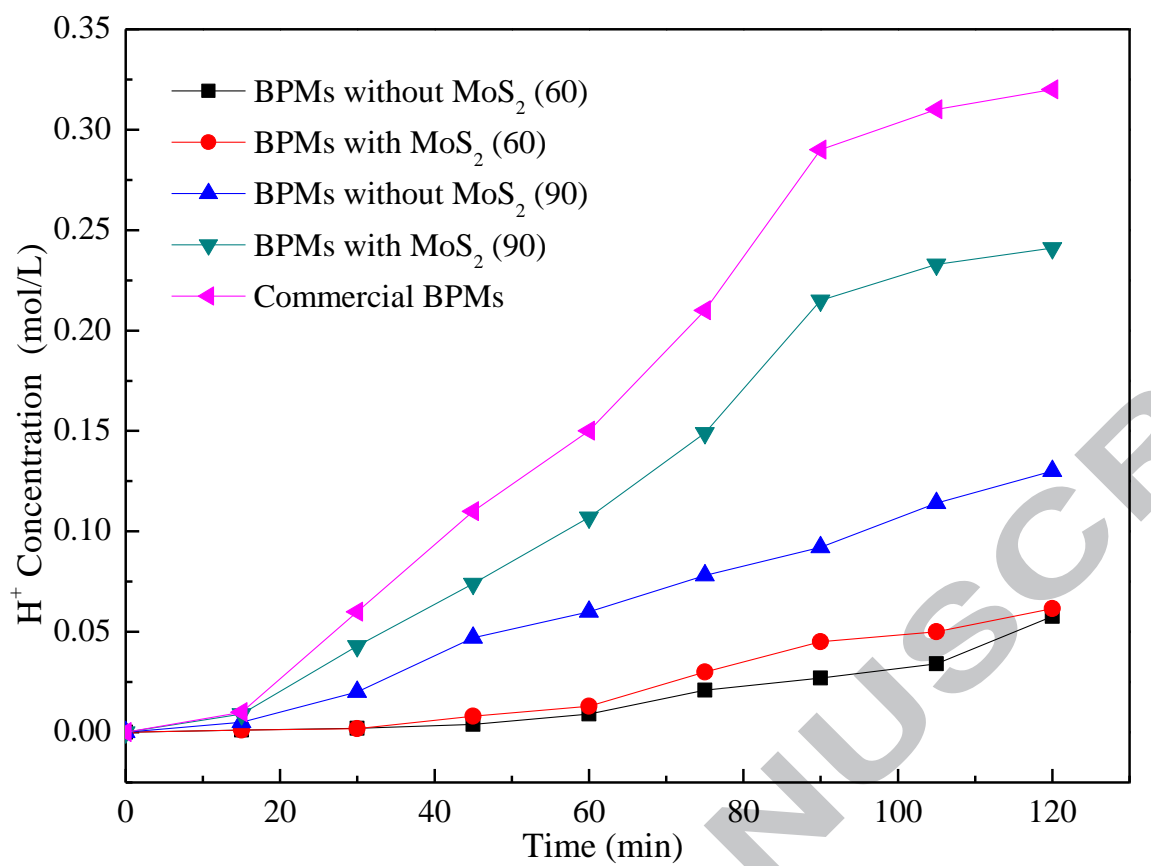

Fig. 10 Variations of the hydrogen ion concentration $\left[\mathrm{H}^{+}\right]$in the acid compartment (BPMs: bipolar membranes)

Fig. 11 shows the voltage drop as a function of time. A lower voltage drop was obtained at higher temperature; however, two-layer membranes have a lower voltage drop than three-layer bipolar membranes. This is because when no $\mathrm{MoS}_{2}$ exists in the interfacial layer, the leakage of co-ions will reduce the voltage drop. Therefore, $\mathrm{MoS}_{2}$ could efficiency promote the water dissociation.

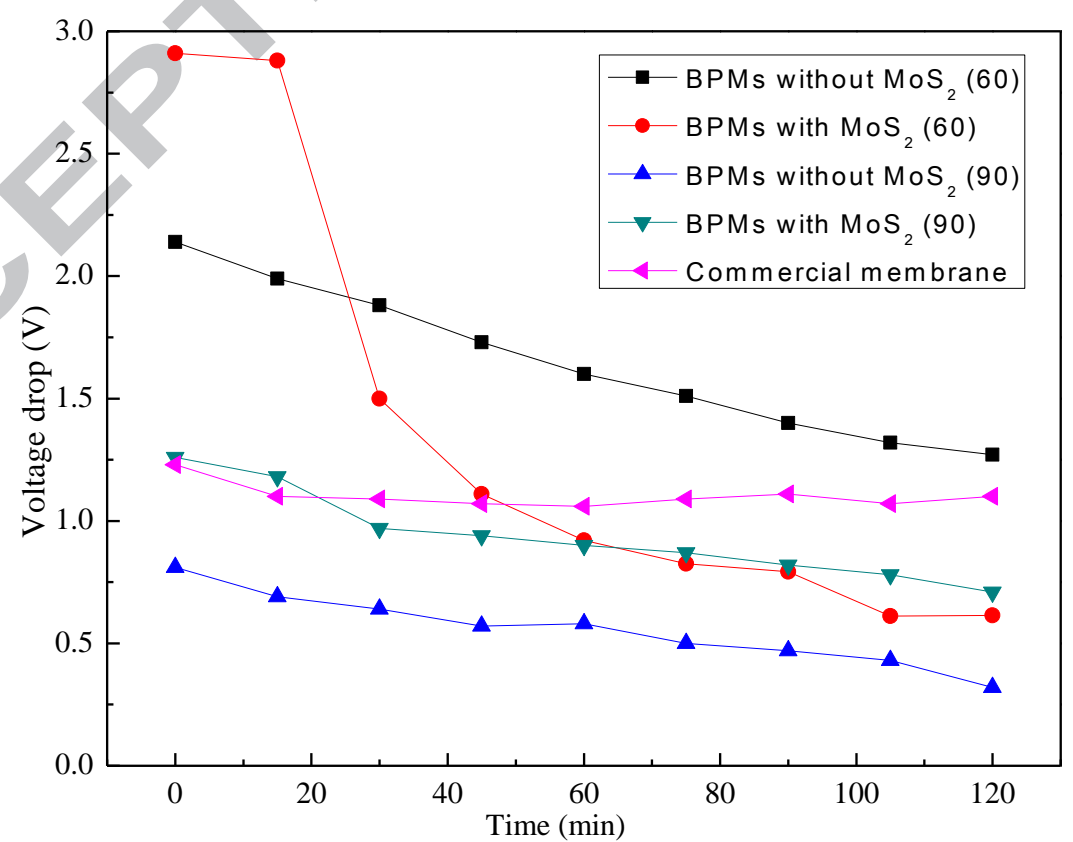

Fig. 11 The change of voltage drops across the bipolar membranes with time (BPMs: bipolar membranes) 
Fig. 12 shows the current efficiency and energy consumption of bipolar membranes prepared in different conditions. It can be concluded that amination at higher temperature tends to improve the current efficiency, with a decreased energy consumption. This is mainly because at higher temperature, the amination reaction occurs easily, and the electric field strength at the interface layer was enhanced. At lower temperature, the current efficiency for the membranes with $\mathrm{MoS}_{2}$ increased while the energy consumption was similar. By introducing $\mathrm{MoS}_{2}$, although water splitting was enhanced, the resistance of bipolar membranes was also increased, which results in a higher energy consumption. For the method applied at higher temperature, the same phenomenon with respect to the current efficiency can be seen, but the energy consumption was reduced. This can be explained by two reasons. First, co-ion leakage reduced the energy consumption; second, protons generated by water splitting can compensate the current to some extent. From the view point of current efficiency and acid production, $\mathrm{MoS}_{2}$ can be a good catalyst for bipolar membranes in water dissociation. Although the acid production and current efficiency is not as high as the commercial membranes, further improvement is underway to change the concentration and size of $\mathrm{MoS}_{2}$, the thickness and materials of the anion and cation exchange layer.

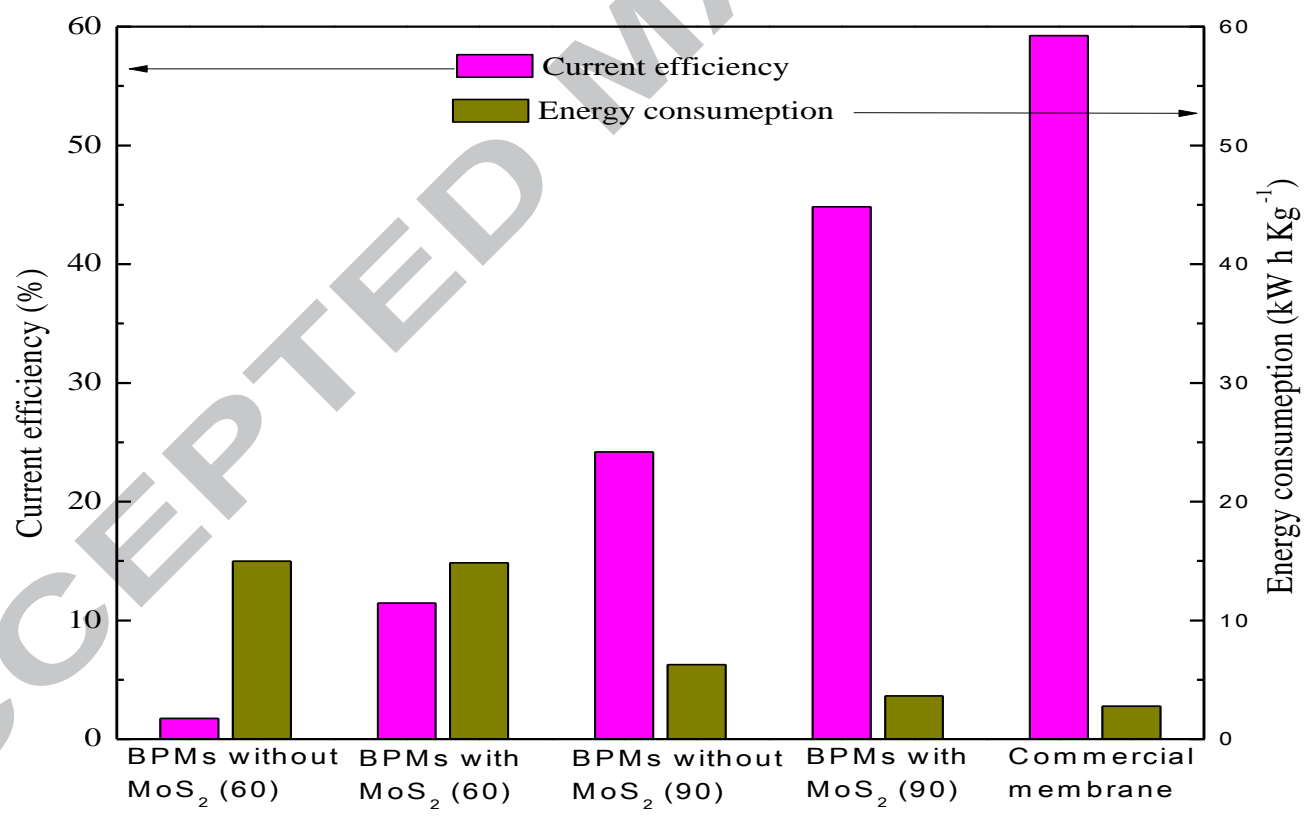

Fig. 12 Current efficiency and energy consumption of different membranes during water dissociation (BPMs: bipolar membranes)

To further analyse the influence of current density over acid production, bipolar membranes prepared with $\mathrm{MoS}_{2}$ at $90^{\circ} \mathrm{C}$ were used at current densities of 20, 30, 40 and $50 \mathrm{~mA} / \mathrm{cm}^{2}$. As presented in Fig. 13, the production of acid is dependent on the current density, the higher the applied current density, the higher concentration of the produced acid, because the mass transport rate of $\mathrm{SO}_{4}{ }^{2-}$ will become higher when the current density increases. At the same time, the water dissociation rate is accelerated with an increase in current according to the Second Wien effect. However, the current 
efficiency decreased, which is caused by co-ion leakage and diffusion through the ion exchange membranes. The relationship between the energy consumption and current density revealed that the energy consumption increases as the current density increases. The increase in the energy consumption was attributed to energy consumed to overcome the electrical resistance while the current density increases. The current efficiency increases and energy consumption decreases as the current density decreases. As a result, the lower current density is more appropriate when considering the efficiency and consumption of energy.

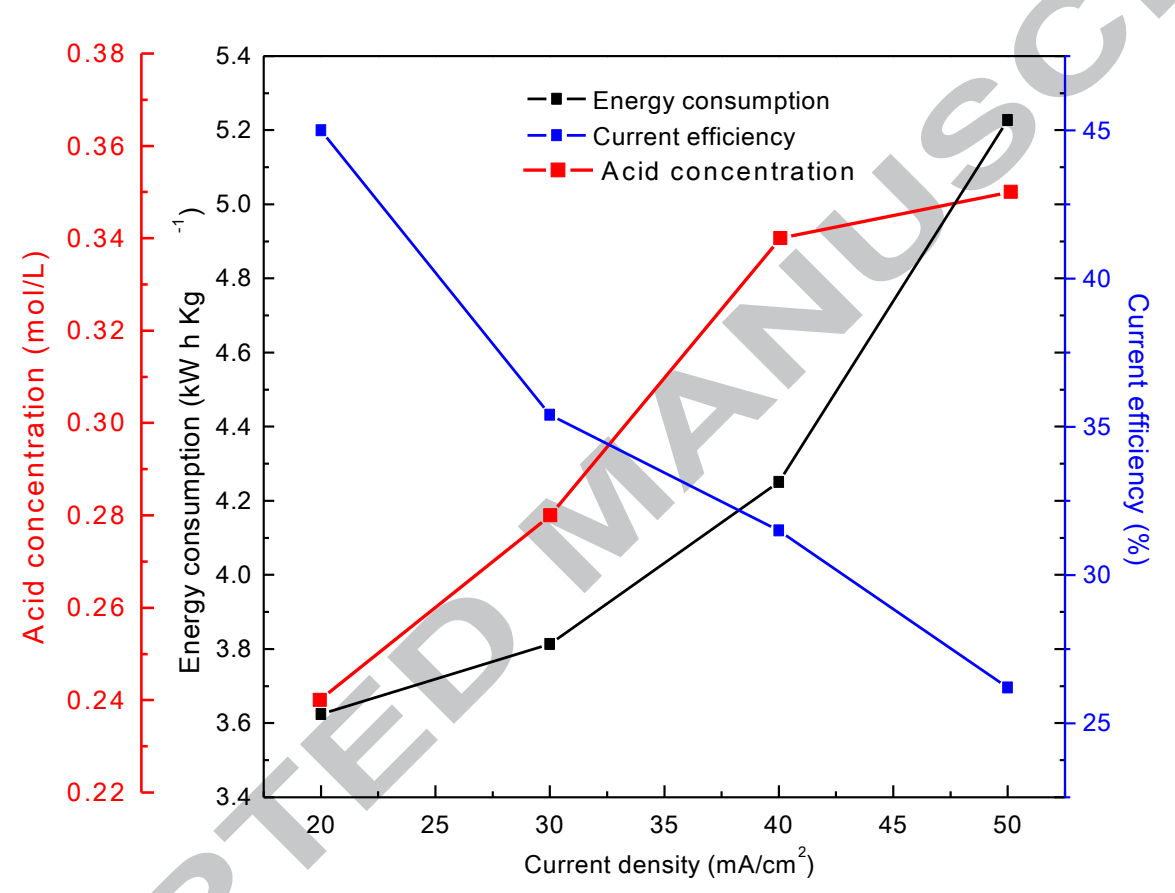

Fig. 13 Comparison of the current efficiency and energy consumption at various current densities

\section{Conclusions}

Novel sandwiched bipolar membranes composed of SPES/MoS $2 / \mathrm{PECH-PVDF}$ were successfully fabricated. The optimal bipolar membranes have been tested for different properties such as ion exchange capacity, voltage drop, acid production and energy consumption. A bipolar membrane with IEC of $0.96 \mathrm{mmol} / \mathrm{g}$ for cation exchange layer and $1.03 \mathrm{mmol} / \mathrm{g}$ for anion exchange layer, showed high ion transport rate for both cation exchange layer $(0.19 \mathrm{~mol} / \mathrm{L})$ and anion exchange layer $(0.23$ $\mathrm{mol} / \mathrm{L}$ ). In addition, a high water uptake of $71.6 \%$ and comparatively lower contact angle provide a super hydrophilic environment necessary for water transfer from membrane surface to inter layer. The prepared bipolar membranes with $\mathrm{MoS}_{2}$ at $90{ }^{\circ} \mathrm{C}$ exhibit an outstanding performance with a higher current efficiency of $45 \%$ and a lower energy consumption of $3.6 \mathrm{~kW} / \mathrm{h} \cdot \mathrm{kg}$ compared to a bipolar membrane without 
$\mathrm{MoS}_{2}$. As a consequence, a monolayer of $\mathrm{MoS}_{2}$ on the inter layer of the bipolar membrane can serve as a good catalyst to reduce the high activation energy of water dissociation. In a broader context, further study of $\mathrm{MoS}_{2}$ as catalyst should be studied referring to optimization of conditions and industrial applications.

\section{Acknowledgement}

J.L. sincerely acknowledges the financial support provided by China Scholarship Council (CSC) of the Ministry of Education, P.R. China. 


\section{References}

[1] K. Zhang, M. Wang, D. Wang, C. Gao, The energy-saving production of tartaric acid using ion exchange resin-filling bipolar membrane electrodialysis, J. Membr. Sci. 341 (2009) 246-251.

[2] C. Huang, T. Xu, M. L. Jacobs, Regenerating flue - gas desulfurizing agents by bipolar membrane electrodialysis, AIChE J. 52 (2006) 393-401.

[3] W. Timbuntam, K. Sriroth, K. Piyachomkwan, Y. Tokiwa, Application of bipolar electrodialysis on recovery of free lactic acid after simultaneous saccharification and fermentation of cassava starch, Biotechnol. Lett. 30 (2008) 1747-1752.

[4] N. Drouiche, H. Grib, N. Abdi, H. Lounici, A. Pauss, N. Mameri, Electrodialysis with bipolar membrane for regeneration of a spent activated carbon, J. Hazard. Mater. 170 (2009) 197-202.

[5] H. Strathmann, H. -J. Rapp, B. Bauer, C. Be11, Theoretical and practical aspects of preparing bipolar membranes, Desalination 90 (1993) 303-323.

[6] S. Abdu, K. Sricharoen, J.E. Wong, E. S. Muljadi, T. Melin, M. Wessling, Catalytic polyelectrolyte multilayers at the bipolar membrane interface, ACS Appl. Mat. Interfaces 5 (2013) 10445-10455.

[7] C. Huang, T. Xu, Electrodialysis wi th bipolar membranes for sustainable development, Environ. Sci. Technol. 40 (2006) 5233-5243.

[8] T. - j. Zhou, Y. -y. Hu, R. -y. Chen, X. Zheng, X. Chen, Z. Chen, J. -q. Zhong, Preparation and characterization of bipolar membranes modified by photocatalyst nano-Zn0 and nano-Ce0 2, App1. Surf. Sci. 258 (2012) 4023-4027.

[9] S. Abdu, M. -C. s. Martí-Calatayud, J.E. Wong, M. García-Gabaldón, M. Wessling, Layer-by-layer modification of cation exchange membranes controls ion selectivity and water splitting, ACS Appl. Mat. Interfaces 6 (2014) 1843-1854.

[10] R. -Y. Chen, Z. Chen, X. Zheng, X. Chen, S. -Y. Wu, Preparation and characterization of mSA/mCS bipolar membranes modified by CuTsPc and CuTAPc, J. Membr. Sci. 355 (2010) $1-6$.

[11] Z. Xing, X. Yang, A. M. Asiri, X. Sun, Three-Dimensional Structures of MoS2@ Ni Core/Shel1 Nanosheets Array toward Synergetic Electrocatalytic Water Splitting, ACS App1. Mat. Interfaces 8 (2016) 14521-14526.

[12] J. Zhang, T. Wang, D. Poh1, B. Rellinghaus, R. Dong, S. Liu, X. Zhuang, X. Feng, Interface Engineering of MoS2/Ni3S2 Heterostructures for Highly Enhanced Electrochemical Overall - Water-Splitting Activity, Angew. Chem. 128 (2016) 6814-6819.

[13] Y. Wang, C. Cong, C. Qiu, T. Yu, Raman spectroscopy study of lattice vibration and crystallographic orientation of monolayer MoS2 under uniaxial strain, Sma11 9 (2013) 2857-2861.

[14] P. Joo, K. Jo, G. Ahn, D. Voiry, H. Y. Jeong, S. Ryu, M. Chhowalla, B. -S. Kim, Functional polyelectrolyte nanospaced MoS2 multilayers for enhanced photoluminescence, Nano Lett. 14 (2014) 6456-6462.

[15] Y. Ouyang, C. Ling, Q. Chen, Z. Wang, L. Shi, J. Wang, Activating inert basal planes 
of MoS2 for hydrogen evolution reaction through the formation of different intrinsic defects, Chem. Mater. 12 (2016) 4390-4396.

[16] K. K. Ghuman, S. Yadav, C. V. Singh, Adsorption and Dissociation of H20 on Monolayered MoS2 Edges: Energetics and Mechanism from ab Initio Simulations, J. Phys. Chem. C 119 (2015) 6518-6529.

[17] G. Levita, P. Restuccia, M. Righi, Graphene and MoS 2 interacting with water: A comparison by ab initio calculations, Carbon 107 (2016) 878-884.

[18] J. Wang, W. Zhang, Y. Wang, W. Zhu, D. Zhang, Z. Li, J. Wang, Enhanced Exfoliation Effect of Solid Auxiliary Agent On the Synthesis of Biofunctionalized MoS2 Using Grindstone Chemistry, Part. Part. Syst. Char. (2016).

[19] M. -S. Kang, Y.-J. Choi, S. -H. Moon, Effects of inorganic substances on water splitting in ion-exchange membranes: II. Optimal contents of inorganic substances in preparing bipolar membranes, J. Colloid Interface Sci. 273 (2004) 533-539.

[20] M. Safarpour, A. Khataee, V. Vatanpour, Effect of reduced graphene oxide/Ti0 2 nanocomposite with different molar ratios on the performance of PVDF ultrafiltration membranes, Sep. Purif. Technol. 140 (2015) 32-42.

[21] A. Muthumeena1, S. Neelakandan, D. Rana, T. Matsuura, P. Kanagaraj, A. Nagendran, Sulfonated polyethersulfone (SPES) - charged surface modifying macromolecules (cSMMs) blends as a cation selective membrane for fuel cells, Fuel cells 14 (2014) 853-861. [22] W. Shi, M. Yang, H. Li, R. Zhou, H. Zhang, Preparation and Characterization of Sulfonated Poly (Ether Sulfone) (SPES)/Phosphotungstic Acid (PWA) Hybrid Membranes for Biodiesel Production, Catal. Lett. 145 (2015) 1581-1590.

[23] K. J. Berean, J. Z. Ou, T. Daeneke, B. J. Carey, E. P. Nguyen, Y. Wang, S. P. Russo, R. B. Kaner, K. Kalantar - zadeh, 2D MoS2 PDMS nanocomposites for N02 separation, Smal1 11 (2015) 5035-5040.

[24] E. P. Nguyen, B. J. Carey, T. Daeneke, J. Z. Ou, K. Latham, S. Zhuiykov, K. Kalantar-zadeh, Investigation of two-solvent grinding-assisted liquid phase exfoliation of layered MoS2, Chem. Mater. 27 (2014) 53-59.

[25] A. E. Allegrezza Jr, E. C. Bellantoni, Porous membrane formed from interpenetrating polymer network having hydrophilic surface, in, Google Patents, 1992.

[26] G. -J. Hwang, S. -G. Lim, S. - Y. Bong, C. - H. Ryu, H. - S. Choi, Preparation of anion exchange membrane using polyvinyl chloride (PVC) for alkaline water electrolysis, Korean J. Chem. Eng. 32 (2015) 1896-1901.

[27] W. -J. Lau, A. F. Ismail, Effect of SPEEK content on the morphological and electrical properties of PES/SPEEK blend nanofiltration membranes, Desalination 249 (2009) 996-1005.

[28] X. Ling, C. Jia, J. Liu, C. Yan, Preparation and characterization of sulfonated poly (ether sulfone)/sulfonated poly (ether ether ketone) blend membrane for vanadium redox flow battery, J. Membr. Sci. 415 (2012) 306-312.

[29] A. Rahimpour, S. Madaeni, S. Zereshki, Y. Mansourpanah, Preparation and characterization of modified nano-porous PVDF membrane with high antifouling property using UV photo-grafting, App1. Surf. Sci. 255 (2009) 7455-7461.

[30] J. Hu, D. Wan, W. Zhu, L. Huang, S. Tan, X. Cai, X. Zhang, Fabrication of a high-stability cross-1inked quaternized poly (epichlorolydrin)/PTFE composite membrane 
via a facile route, ACS Appl. Mat. Interfaces 6 (2014) 4720-4730.

[31] T. Y. Guo, Q.H. Zeng, C.H. Zhao, Q. L. Liu, A.M. Zhu, I. Broadwe11, Quaternized polyepichlorohydrin/PTFE composite anion exchange membranes for direct methano1 alkaline fuel cells, J. Membr. Sci. 371 (2011) 268-275.

[32] R. Simons, Strong electric field effects on proton transfer between membrane-bound amines and water, Nat. 280 (1979) 824-826. 
Highlights

1. $\mathrm{MoS}_{2}$ as advanced catalysts was introduced to the interface of bipolar exchange membranes to enhance water dissociation.

2. Enhanced acid production, higher current efficiency and lower energy consumption was obtained after introducing $\mathrm{MoS}_{2}$ layer catalyzes.

3. High water uptake of membrane provide a super hydrophilic environment necessary for water transfer from membrane surface to inter layer. 